\title{
Trajetória e obra de Norberto Bobbio
}

Tercio Sampaio Ferraz Junior ${ }^{I}$

$N$ ORBERTO Bobbio: trajetória e obra é, seguramente, o livro mais denso que se publicou no Brasil (e quiçá em língua portuguesa) sobre o grande pensador e jurista italiano. Nesse livro, Celso Lafer reúne a série de trabalhos, ora artigos, ora prefácios, ora conferências, ora pequenos ensaios que durante anos (na verdade, de 1980 a 2011), alguns de convivência com o próprio Bobbio, vem elaborado didaticamente e aperfeiçoando em sua sutileza teórica.

Não se trata simplesmente de uma coletânea de escritos, pois vai além. Há um notável esforço de trazer Bobbio vida e obra - a uma espécie de convergência intelectiva sem ser propriamente uma síntese. Afinal, como reconhece Celso Lafer, Bobbio opera não só com uma diversidade de autores, mas com um abrangente e complexo repertório de temas e ideias, no que é "não um filósofo de sínteses impossíveis, mas um filósofo da análise", certamente de natureza mais heurística do que analítica.

Nesse contexto, aponta Celso Lafer, com Ruiz Miguel (1980), que o modo recorrente do trabalho intelectual de Bobbio é o artigo que tem um problema como ponto de partida, cujos termos são esmiuçados para um subsequente encaminhamento com base na análise crítica de diversas posições, sendo a qualidade e a pertinência das suas análises e considerações no trato dos problemas da vida do direito que o tornaram um excepcional ponto de referência para o mundo jurídico.

Ressalta, assim, com Riccardo Guastini (2005), um dos grandes estudiosos da obra jurídica de Bobbio, que o estilo analítico é uma das características mais notáveis de como foi elaborando a sua Teoria do Direito.

Contudo, um estilo analítico que opera com base no dividir, distinguir, seccionar para considerar as coisas nos seus elementos mais simples. Daí a atenção de Celso Lafer para a contraposição da análise à síntese, o que leva Bobbio (1972), na sua defesa da filosofia do direito de juristas em alternativa à dos filósofos, a considerar que é "sempre preferível uma análise sem síntese (do que com frequência se critica os juristas filósofos) a uma síntese sem análise (que é o vício comum dos filósofos juristas)".

O estilo analítico de Bobbio, mostra Celso Lafer, explica, assim, por que sua obra, em todos os campos do conhecimento a que se dedicou, é um contínuo work in progress por meio do qual, por aproximações sucessivas, vai, com base nesse estilo, aprofundando e refinando os temas recorrentes de suas inquietações intelectuais. É por isso que uma parte significativa dos seus livros são reuniões de ensaios em torno de matérias conexas, fugindo a essa regra aqueles livros que, na sua origem, foram cursos universitários provenientes da sua atividade de professor.

Essa característica do pensar heurístico torna, porém, o livro de Celso Lafer uma elaborada tentativa de busca de convergências, aliás muito bem empreendida, ainda que de difícil consecução. Apresentar Bobbio heurístico descritivamente seria, talvez, um empreendimento na forma de um espelho, como sói acon- 
tecer com obras-resumo ou conjunto de resumos de outras obras. Não é o que faz Celso Lafer. Com esteio numa leitura abrangente, meticulosamente anotada e refletida, traz ele à ponderação o Bobbio heurístico em convergência, na busca de um fio condutor, ele próprio heurístico, capaz de esclarecer, iluminar e dar consistência ao teórico do direito e da política, no plano interno e internacional, na ciência e na filosofia e até na sua trajetória de vida.

Tudo começa com o fim: De senectude, livro de Bobbio de grande reflexão sobre a velhice e sobre seu significado sobretudo como um registro de memória que se insere na memória do registro. Ou seja, um ponto na vida capaz de conferir referência ao passado na medida em que o projeta para o futuro.

Celso Lafer principia, heuristicamente, por uma dicotomia: Bobbio homem de ação e de contemplação. Essa dicotomia - vita activa/vita contemplativa - buscada em Hannah Arendt, conduz a uma interessante convergência. De um lado, a passagem de uma atividade que começara na clandestinidade em tempos do fascismo até a nomeação de Bobbio, em 1984, como senatore a vita; de outro, o intelectual, expoente da vertente inovadora de esquerda, cuja reflexão neocontratualista e republicana o conduz ao diálogo fecundo na resistência contra a opressão da direita. Daí a convergência apontada por Celso Lafer na constituição de uma autoridade pública como paradigma da relação entre o intelectual e o político.

Nessa convergência Celso Lafer faz menção ao estranho interesse de Bobbio por Carl Schmitt que considerava o político como a relação entre amigo/inimigo, nesse ponto, verdadeiro antípoda do jurista italiano. E arrisca: Schmitt teria sido para Bobbio como um "sombra", um Dr. Fausto de gênio que vendera sua alma ao diabo. O que me faz lembrar de um texto de Goethe (no Divã ocidental-oriental) em que a tragédia de Fausto é anunciada e que muito tem a ver com a dicotomia e a dramaticidade da convergência: "O sentido amplia, mas paralisa; a ação vivifica, mas bitola".

Bobbio, na velhice, relata as experiências penosas impostas pelas limitações físicas da idade. Fausto, que se entrega à ação vivificada e sem peias, perdendo o senso, olha para o futuro. Ao contrário de Bobbio que, laico em sede de crença numa outra vida, recorre à memória como meio de sobreviver. Ou seja, olha para o passado. E nisso, como bem aponta Celso Lafer, encontra paz e não angústia.

A paz é o tema da guerra, na reflexão de Bobbio. E vice-versa. Aí também encontra Celso Lafer seu fio condutor na coerência do teórico e do político. De um lado, política internacional é politica do poder. Hobbes, um dos preferidos de Bobbio, estampa nisso uma realidade incontornável. Para enfrentá-la, sem desmerecê-la, recorre à mão de Grócio e Kant. Assim, de outro lado, política internacional é também política jurídica, igualmente uma realidade, um dado de sociabilidade e de razão, donde a ordem internacional.

Entre a guerra e a paz converge Bobbio para um realismo nem pacifista nem belicoso. $\mathrm{Na}$ linguagem metafórica da mosca dentro da garrafa, do peixe na rede e do homem no labirinto, Celso Lafer mostra a importância da terceira hipótese: viver num mundo de becos sem saída como reflexão sobre os caminhos da paz nos labirintos da guerra. 
Daí a convergência para uma insistência permanente na busca de uma luz fugidia, capaz de iluminar o espaço presente, ainda que se obscureça poucos passos depois. O que Celso Lafer chama de "a paixão pela luz e a perseverança da devoção", traços característicos da reflexão do grande jurista. Algo que particularmente desponta nos largos e percucientes textos de Celso Lafer dedicados ao delicado tema da guerra justa que, em Bobbio, passa pelas armadilhas proporcionadas pela guerra fria até o mundo recente da hegemonia norte-americana da guerra do Iraque. E desemboca na reflexão do próprio Celso Lafer, ele mesmo um diplomata e um pensador, sobre o papel da ONU não como um tertium super partes, mas como um tertium inter partes que enfrenta sempre o angustioso desafio de exercer, embora nem sempre, o papel de um tertium juxta partes.

Esse dilema convoca Celso Lafer a examinar a temática dos direitos humanos, desde sua positivação numa declaração constitucional, à sua generalização por progressivo reconhecimento, à sua internacionalização numa carta (caso da ONU) até sua especificação difícil e complicada em diversos destinatários particulares no seio da generalidade (a mulher, os idosos, o deficiente, a criança, os homossexuais).

A dicotomia libertas/potestas atravessa a reflexão de Bobbio numa heurística penosa a percorrer labirintos ardilosos: a prevalência dos interesses, público/ privado, a armadilha da hegemonia individual/social, o papel da tecnologia hodierna intimidade/transparência. Daí a convergência buscada na hegemonia das regras do jogo, o que significa uma democracia de tolerantes, própria dos sábios e dos serenos, numa democracia de preconceitos, própria dos contestadores e dos resistentes.

Bobbio, afinal, não deixa de ter sido um pensador inquieto. $\mathrm{O}$ que se espelha na revolução patente que sofre sua trajetória de teórico do direito, quando, para surpresa dos que acompanhavam seu caminhar pelas estruturas, abre-se para a perspectiva da função. "O Direito é uma ordem coativa que visa à obtenção da segurança coletiva”, e isso basta. Já no enfoque funcionalista, a relação meio/ fim ganha outros relevos, passa mesmo a constituir o cerne da análise, exigindo, do jurista, novas modalizações do fenômeno normativo. E essa sensibilidade para a mudança, sem perder de vista as exigências da racionalidade, é uma das mais importantes características de Norberto Bobbio e a lição mais profunda que se pode extrair de seu pensamento. Por isso ler, entender, interpretar e expor Bobbio é um desafio.

$\mathrm{Na}$ verdade, Bobbio foi um filósofo perguntador: quale? Quale socialismo? Quale democrazia? Quale positivismo? Quale teoria giuridica? Celso Lafer, em seu livro, não deixa de ser também, com genialidade levemente transparente, um perguntador: quale Bobbio?

Afinal, como ele bem mostra, há um Bobbio jurista, um Bobbio político, um Bobbio teórico do direito e da política, um Bobbio internacionalista, um Bobbio filósofo, um jovem Bobbio e um velho Bobbio. Na heurística dicotômica dos vários Bobbio, Celso Lafer resiste à "fúria dos extremos e aos riscos de seus desdobramentos". Nos vários Bobbio encontra, na serenidade intelectual, "a tarefa da inteligência humana de tirar o valor das coisas da obscuridade para a luz", como diz a epígrafe de San Tiago Dantes que usa em seu livro. E aí encon- 


\section{Norberto}

Bobbio:

trajetória

e obra

Celso Lafer

新

LAFER, C. Norberto Bobbio: trajetória

e obra. São Paulo: Perspectiva, 2013.

tra também uma convergência consigo mesmo.

\section{Referências}

BOBBIO, N. Giusnaturalismo e positivismo giuridico. 2.ed. Milano: Ed. di Comunità, 1972. p.44.

GUASTINI, R. La Teoria Generale del Diritto. In: Norberto Bobbio, tra diritto e politica. A cura di Pietro Rossi. Roma; Bari: Laterza, 2005. p.51-79.

MIGUEL, A. R. Estudio Preliminar: Bobbio y el positivismo juridico italiano. In: BOBBIO, N. Contribución a la Teoria del Derecho. Ed. Alfonso Ruiz Miguel. Valencia: Ed. Fernando Torres, 1980. p.16.

Tercio Sampaio Ferraz Junior é professor titular aposentado da Faculdade de Direito da USP.

@ - tercio@sampaioferraz.com.br

${ }^{\text {I }}$ Faculdade de Direito, Universidade de São Paulo, São Paulo/SP, Brazil. 